Gut and Liver, Vol. 11, No. 6, November 2017, pp. 781-788

\title{
Comparison of the Hospital-Acquired Clostridium difficile Infection Risk of Using Proton Pump Inhibitors versus Histamine-2 Receptor Antagonists for Prophylaxis and Treatment of Stress Ulcers: A Systematic Review and Meta- Analysis
}

\author{
Mohamed Azab ${ }^{1}$, Loomee Doo ${ }^{1}$, Daniel H. Doo ${ }^{2}$, Yousif Elmofti ${ }^{1}$, Muazer Ahmed ${ }^{1}$, John Jay Cadavona ${ }^{3}$, Xibei B. Liu ${ }^{3}$, \\ Amaan Shafi ${ }^{3}$, Moon Kyung Joo ${ }^{4}$, and Ji Won Yoo ${ }^{1}$ \\ ${ }^{1}$ Department of Internal Medicine, University of Nevada School of Medicine, Las Vegas, NV, ${ }^{2}$ Department of Global Medicine, Keck School of \\ Medicine, University of Southern California, Los Angeles, CA, ${ }^{3}$ Department of Graduate Education, University of Nevada School of Medicine, \\ Reno, NV, USA, and ${ }^{4}$ Institute of Gastroenterology, Department of Internal Medicine, Korea University College of Medicine, Seoul, Korea
}

See editorial on page 739.

Background/Aims: Although proton pump inhibitors (PPIs) have been widely used for the prevention and treatment of stress gastric ulcers in hospital settings, there are concerns that PPIs increase the risk of Clostridium difficile infection (CDI). However, little is known about the risk of CDI following PPI and histamine-2 receptor antagonist (H2RA) use. We evaluated the comparative hospital-acquired CDI occurrence risk associated with the concurrent use of PPIs versus H2RAs. Methods: A systematic search of PubMed, MEDLINE/Ovid, Cumulative Index to Nursing and Allied Health Literature (CINAHL), Web of Science, and Google Scholar through August 19, 2016, identified 12 studies that reported the hospital-acquired CDI occurrence following H2RA and PPI use for the prevention and treatment of stress gastric ulcers. Random-effects pooled odds ratios and 95\% confidence intervals were estimated. Heterogeneity was measured using $I^{2}$, and a meta-regression analysis was conducted. The Grading of Recommendations Assessment, Development, and Evaluation (GRADE) system was used to assess the overall quality of the evidence. Results: A total of 74,132 patients from 12 observational studies were analyzed. Compared to H2RAs, PPIs increased the risk of CDI by $38.6 \%$ (pooled odds ratio, 1.386; 95\% confidence interval, 1.152 to 1.668 ; $p=0.001 ; I^{2}=42.81 \%$ ). Subgroup analyses of the purpose of study medication use, study site, and study design confirmed the consistency of a greater CDI risk with PPIs than with H2RAs. The overall quality of evidence was rated as low. Conclusions: The use of PPIs for both the prevention and treatment of stress ulcers was associated with a $38.6 \%$ increased risk of hospital-acquired CDI occurrence compared to H2RA use. (Gut Liver 2017;11:781-788)

Key Words: Clostridium; Stomach ulcer; Histamine antagonists; Meta-analysis; Proton pump inhibitors

\section{INTRODUCTION}

Clostridium difficile is a spore forming, toxin producing, gram positive anaerobic bacterium. It was first identified as the cause of antibiotic associated diarrhea in 1978. ${ }^{1}$ Annually, 453,000 new cases occur in the United States with one in four cases occurring in the hospital and a mortality rate of approximately $6 \%{ }^{2}$ Since $C$. difficile infection (CDI) is highly transmissible via the fecal-oral route, strict contact isolation is required per hospital infection control. ${ }^{3,4}$ Beyond well-known risk factors, proton pump inhibitor (PPI) use for gastric acid suppression treatment has been an emerging risk factor of CDI. ${ }^{5-}$ ${ }^{16}$ Studies have shown that both PPIs and histamine-2 receptor antagonists (H2RAs) are associated with an increased risk of CDI. ${ }^{9,11,12}$ Bacterial overgrowth resulting from gastric acid suppression treatment has been suggested as an explanation for the vulnerable gut environment that increases CDI occurrence. ${ }^{17}$ In addition, since 2012, the Food and Drug Administration (FDA) has expressed public concerns of CDI occurrence by gastric acid suppression treatment. ${ }^{18}$ A series of meta-analysis studies sup-

Correspondence to: Ji Won Yoo

Department of Internal Medicine, University of Nevada School of Medicine, 1701 West Charleston Blvd. \#230, Las Vegas, NV 89102, USA

Tel: +1-702-671-6496, Fax: +1-702-671-2376, E-mail: jwyoo@medicine.nevada.edu

Received on November 23, 2016. Revised on December 21, 2016. Accepted on December 21, 2016. Published online May 17, 2017

pISSN 1976-2283 eISSN 2005-1212 https://doi.org/10.5009/gnl16568

@) This is an Open Access article distributed under the terms of the Creative Commons Attribution Non-Commercial License (http://creativecommons.org/licenses/by-nc/4.0) which permits unrestricted non-commercial use, distribution, and reproduction in any medium, provided the original work is properly cited. 
ported this public concern of the association between gastric acid suppression and CDI occurrence. ${ }^{19-22}$ Gastric acid suppression can be achieved by two different classes of medications PPI and H2RA. There is an urgent need of comparing CDI risk from PPI and H2RA. In 2012, Kwok et al. ${ }^{20}$ reported subgroup analysis that H2RAs were less likely to cause CDI compared to PPIs. However, this meta-analysis encountered a substantial heterogeneity $\left(I^{2}, 60 \%\right.$ to $\left.85 \%\right) .{ }^{20}$ Then after, MacLaren et al..$^{23}$ reported greater risk of gastrointestinal (GI) hemorrhage, pneumonia and CDI with PPI compared to H2RA use in an intensive care unit setting. This study limited study participants to critically ill patients on mechanical ventilation. ${ }^{23}$ As such, there is little insight regarding the relation between PPI or H2RA and hospitalacquired CDI. Current meta-analysis is an important addition to medical literature which will guide the health care professional on gastric acid suppression choices in the hospital setting.

\section{MATERIALS AND METHODS}

\section{Search strategy}

We performed a literature search using the keywords "Clostridium," "Proton pump inhibitor," "Histamine antagonist," "Gastric ulcer," or "Stress ulcer" in various combinations to identify original studies published in English from PubMed,
MEDLINE/Ovid, Cumulative Index to Nursing and Allied Health Literature (CINAHL), Web of Science, and Google Scholar databases through August 19, 2016.

\section{Inclusion and exclusion criteria}

We included studies that compared the CDI occurrence risks from PPI and H2RA in hospitalized adults. We excluded studies that analyzed patients in nursing homes or living at home.

\section{Study selection and data extraction}

Two authors (M. Azab and J.W.Y.) independently screened titles and abstracts. They obtained full articles that met the inclusion and exclusion criteria and after an independent review, they extracted the data. For all phases, discrepancies were resolved in consultation with three other authors (L.D., D.H.D., and Y.E.). We also hand-searched the eligible articles. Twentynine studies relevant to inclusion criteria were added. The actual numbers of CDI cases were collected from tables and manuscript text in each study. When actual data was not presented in certain studies, three authors (M. Ahmed, J.J.C., and X.B.L.) directly contacted corresponding authors of their studies to obtain the data. Since data was from previously published studies, an Institutional Review Board approval was waived. Finally, twelve studies were selected. Fig. 1 presents the study selection process

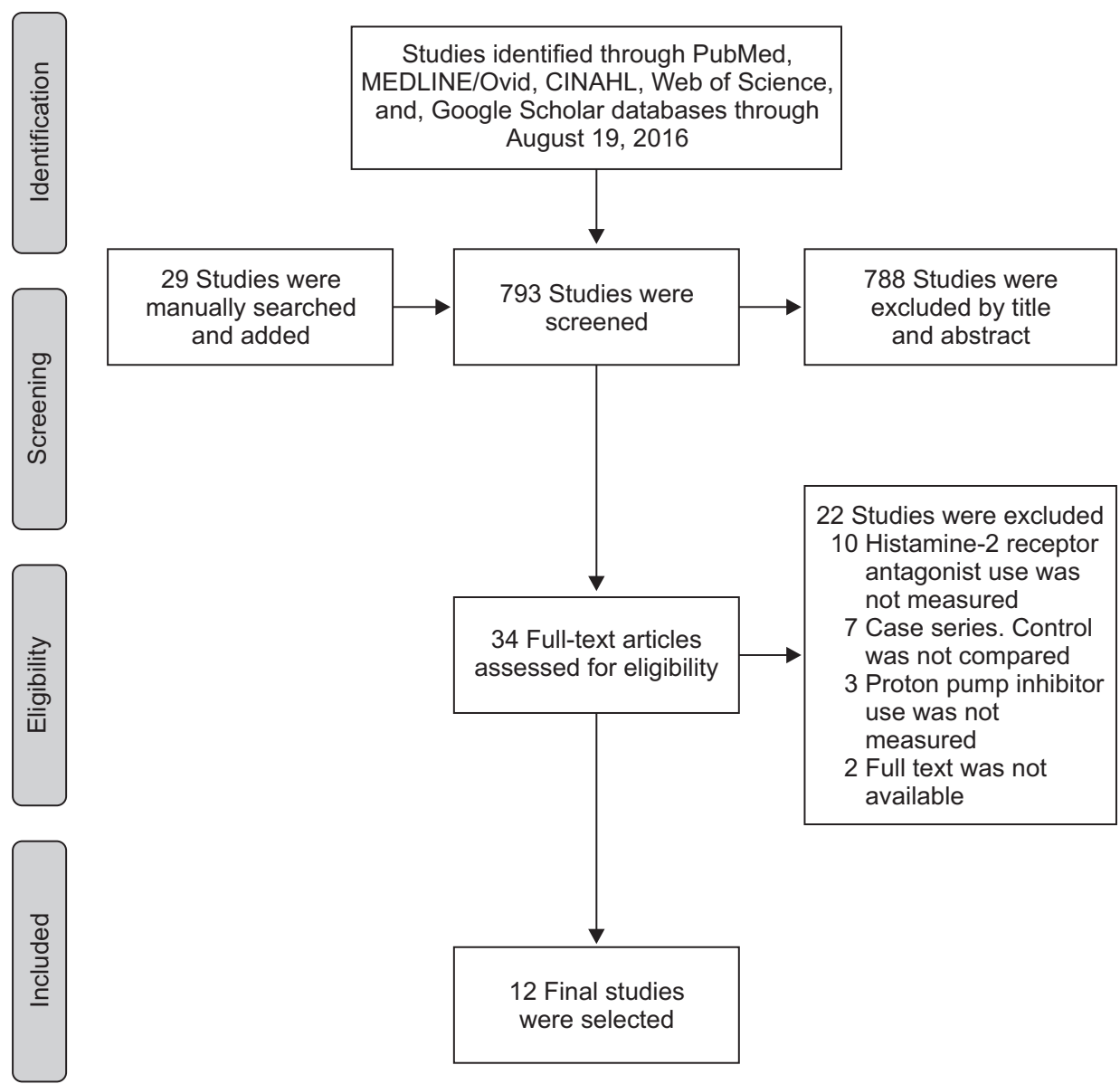

Fig. 1. Study selection process. CINAHL, Cumulative Index of Nursing and Allied Health Literature. 
Table 1. Summary of Studies

\begin{tabular}{|c|c|c|c|c|c|c|c|}
\hline \multirow{3}{*}{ Author (year) } & \multirow{3}{*}{$\begin{array}{c}\text { Study } \\
\text { participants }\end{array}$} & \multirow{3}{*}{ Study site } & \multirow{3}{*}{ Study design } & \multicolumn{4}{|c|}{ Clostridium difficile infection risk } \\
\hline & & & & \multicolumn{2}{|c|}{ PPI } & \multicolumn{2}{|c|}{ H2RA } \\
\hline & & & & $\mathrm{OR}^{*}$ & p-value & $\mathrm{OR}^{*}$ & p-value \\
\hline Shah et al. $(2000)^{5}$ & 95 & South Wales & Case-control & \multicolumn{2}{|c|}{ NA } & \multicolumn{2}{|c|}{ NA } \\
\hline Muto et al. $(2005)^{6}$ & 432 & USA & Case-control & 2.4 & - & 2.0 & - \\
\hline Kazakova et al. (2006) ${ }^{7}$ & 70 & USA & Case-control & 3.14 & 0.003 & 2.69 & 0.02 \\
\hline Jayatilaka et al. $(2007)^{8}$ & 322 & USA & Case-control & 2.61 & $<0.001$ & 1.06 & Non-significant \\
\hline Dubberke et al. $(2007)^{9}$ & 1,451 & USA & Case-control & 4.2 & - & 3.0 & - \\
\hline Aseeri et al. $(2008)^{10}$ & 123 & USA & Case-control & 3.6 & $<0.001$ & 2.14 & 0.082 \\
\hline Howell et al. (2010) ${ }^{11}$ & 60,531 & USA & Cohort & 1.74 & $<0.001$ & 1.53 & 0.001 \\
\hline Loo et al. $(2011)^{12}$ & 2,145 & Canada & Case-control & 2.64 & - & 0.98 & - \\
\hline Stevens et al. $(2011)^{13}$ & 7,405 & USA & Cohort & 4.50 & $<0.001$ & 1.7 & 0.25 \\
\hline Barletta et al. (2013) ${ }^{14}$ & 148 & USA & Case-control & 1.14 & 0.018 & \multicolumn{2}{|c|}{ NA } \\
\hline Barletta et al. (2014) ${ }^{15}$ & 429 & USA (ICU only) & Case-control & 2.19 & 0.005 & 1.12 & 0.628 \\
\hline Ro et al. (2016) ${ }^{16}$ & 981 & Korea (ICU only) & Cohort & 3.0 & 0.003 & \multicolumn{2}{|c|}{ NA } \\
\hline
\end{tabular}

PPI, proton pump inhibitor; OR, odds ratio; H2RA, histamine-2 receptor antagonist; NA, not applicable; ICU, intensive care unit. ${ }^{*} \mathrm{OR}>1$ indicates that either PPI or H2RA increases the risk of $C$. difficile infection compared to no treatment.

Table 2. Quality of Evidence

\begin{tabular}{|c|c|c|c|c|c|c|}
\hline \multirow[t]{2}{*}{ Outcome } & \multicolumn{2}{|c|}{$\begin{array}{l}\text { Anticipated absolute effects* } \\
\qquad(95 \% \mathrm{CI})\end{array}$} & \multirow{2}{*}{$\begin{array}{l}\text { Relative effect } \\
\mathrm{OR}^{\dagger}(95 \% \mathrm{CI})\end{array}$} & \multirow{2}{*}{$\begin{array}{l}\text { No. of } \\
\text { participants } \\
\text { (studies) }\end{array}$} & \multirow{2}{*}{$\begin{array}{l}\text { Quality of the } \\
\text { evidence } \\
\text { (GRADE) }\end{array}$} & \multirow{2}{*}{ Comment } \\
\hline & Risk with H2RA & Risk with PPI & & & & \\
\hline \multirow{5}{*}{$\begin{array}{l}\text { Clostridium difficile } \\
\text { infection occurrence } \\
\text { from PPI vs H2RA }\end{array}$} & 26 per $1,000(95 \% \mathrm{CI})$ & 36 per $1,000(30-43)$ & $1.38(1.15-1.67)$ & 74,132 & $2 / 4$ & No serious limitations \\
\hline & & & & (12 observational & Low & were found in risk of \\
\hline & & & & studies) & & bias, consistency, \\
\hline & & & & & & directness, precision, \\
\hline & & & & & & and publication bias. \\
\hline
\end{tabular}

CI, confidence interval; H2RA, histamine-2 receptor antagonist; PPI, proton pump inhibitor; OR, odds ratio; GRADE, Grading of Recommendations Assessment, Development, and Evaluation.

${ }^{*}$ Number of $C$. difficile infection per 1,000 persons; ${ }^{\dagger} \mathrm{OR}>1$ indicates $C$. difficile risk from PPIs is higher than the risk from H2RAs.

in accordance with the Preferred Reporting Items for Systematic Reviews and Meta-Analyses statement. ${ }^{24}$ A summary of studies is shown in Table 1.

\section{Quality assessment}

We used the Grading of Recommendations Assessment, Development, and Evaluation (GRADE) system to assess overall quality of evidence for each outcome. ${ }^{25}$ The overall quality of evidence took into consideration the following five domains: risk of bias, consistency, directness, precision, and publication bias. $^{25}$ The GRADE system can be used for rating the quality of evidence (high, moderate, low, and very low). ${ }^{25}$ Meta-analysis from observational studies starts from low quality of evidence. The quality of evidence may decrease when there is serious limitation of any of the five domains. We used optimal information size (OIS) calculations as an objective measure of impre- cision for grading evidence, as a priori of risk increase by $25 \%$ from PPI with an $\alpha=0.05$ and $\beta=0.80$ compared to CDI occurrence risk from H2RA. ${ }^{26}$ Publication bias was assessed by visual inspection of funnel plots and Egger regression analysis. The GRADEpro software (McMaster University and Evidence Prime Inc., Hamilton, ON, Canada) was used to prepare the quality of evidence as shown in Table $2 .^{27}$

\section{Data synthesis and analysis}

We combined individual study results to calculate the pooled odds ratio (OR) and 95\% confidence intervals (CI) using the random effects method. ${ }^{28}$ Between-study heterogeneity was assessed using the $I^{2}$ static values of 50\%, representing extensive statistical inconsistency. Subgroup analysis was performed to examine effects of medication use purpose, study site, and study design. Meta-regression analysis was performed to predict 
Table 3. Baseline Characteristics of the Study Participants by Clostridium difficile Infection Status

\begin{tabular}{lccc}
\hline \multicolumn{1}{c}{ Variable } & C. difficile infection $(\mathrm{n}=2,235)$ & Absence of $C$. difficile infection $(\mathrm{n}=71,897)$ & $\mathrm{p}$-value \\
\hline Age, yr & $68.74 \pm 3.41$ & $67.88 \pm 2.20$ & 0.294 \\
Sex (male), \% & $52.20(3.28)$ & $51.96(2.54)$ & 0.539 \\
Race (white), \% & $79.28(13.42)$ & $78.84(14.70)$ & 0.360 \\
Intensive care unit stay, \% & $58.32(16.72)$ & $39.57(7.14)$ & $<0.001$ \\
Antibiotics use, \% & $86.58(6.09)$ & $84.90(7.13)$ & 0.328 \\
\hline
\end{tabular}

Data are presented as mean \pm SD or observed (SD).

Study name

$\begin{array}{lcccc} & \begin{array}{c}\text { Odds } \\ \text { ratio }\end{array} & \begin{array}{c}\text { Lower } \\ \text { limit }\end{array} & \begin{array}{c}\text { Upper } \\ \text { limit }\end{array} & \text { p-value } \\ \text { Shah et al. }(2000)^{5} & 0.889 & 0.397 & 1.993 & 0.775 \\ \text { Muto et al. }(2005)^{6} & 1.281 & 0.846 & 1.939 & 0.242 \\ \text { Kazakova et al. }(2006)^{7} & 1.286 & 0.500 & 3.306 & 0.602 \\ \text { Jayatilaka et al. }(2007)^{8} & 1.543 & 0.797 & 2.989 & 0.198 \\ \text { Dubberke et al. }(2007)^{9} & 1.000 & 0.802 & 1.248 & 0.998 \\ \text { Aseeri et al. }(2008)^{10} & 0.897 & 0.362 & 2.222 & 0.814 \\ \text { Howell et al. }(2010)^{11} & 1.611 & 1.245 & 2.084 & 0.000 \\ \text { Loo et al. }(2011)^{12} & 1.554 & 0.972 & 2.485 & 0.066 \\ \text { Stevens et al. }(2011)^{13} & 1.513 & 0.978 & 2.341 & 0.063 \\ \text { Barletta et al. }(2013)^{14} & 1.962 & 0.945 & 4.072 & 0.071 \\ \text { Barletta et al. }(2014)^{15} & 1.227 & 0.795 & 1.894 & 0.355 \\ \text { Ro et al. }(2016)^{16} & 3.547 & 1.704 & 7.386 & 0.001 \\ & 1.386 & 1.152 & 1.668 & 0.001\end{array}$

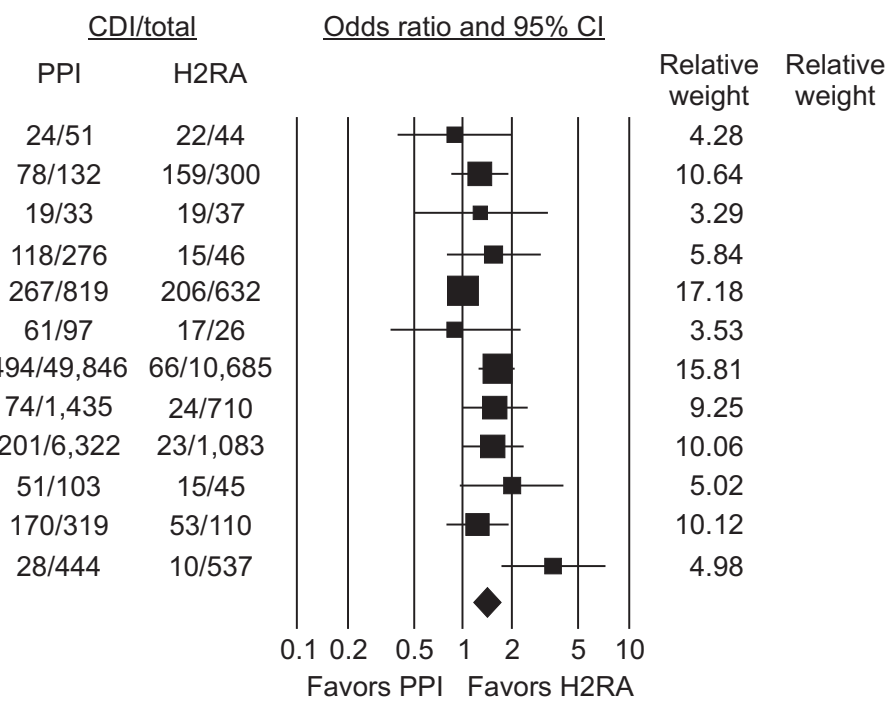

Fig. 2. Meta-analysis results. Comparison of the Clostridium difficile infection (CDI) risk following proton pump inhibitor (PPI) and histamine-2 receptor antagonist (H2RA) use.

CI, confidence interval.

whether age, gender, or antibiotics use would be associated with hospital-acquired CDI occurrence risk. Baseline characteristics of study participants were aggregated from 12 analyzed studies as shown in Table 3. To compare the baseline characteristics by CDI status, chi-square analysis for categorical variables and ttest analysis for continuous variable was performed. Kwok et al. ${ }^{20}$ performed subgroup analysis of CDI occurrence risks from "PPI vs control" and "H2RA vs control." Supplementary Table 1 compared the studies analyzed by current and Kwok's metaanalysis. ${ }^{20}$ All analyses were performed in SPSS version 24 (IBM Corp., Armonk, NY, USA) and Comprehensive Meta-Analysis version 3 (Biostat Inc., Englewood, NJ, USA). A two-sided pvalue $<0.05$ was considered statistically significant.

\section{RESULTS}

A total of 74,132 patients from 12 observational studies were analyzed. Baseline characteristics from pooled study participants are reported in Table 3. Characteristics were grouped by CDI status: $\mathrm{CDI}(\mathrm{n}=2,235)$ versus absence of $\mathrm{CDI}(\mathrm{n}=71,897)$. There was no statistical significance between the participants of CDI and non-CDI except for intensive care unit use. CDI group par-

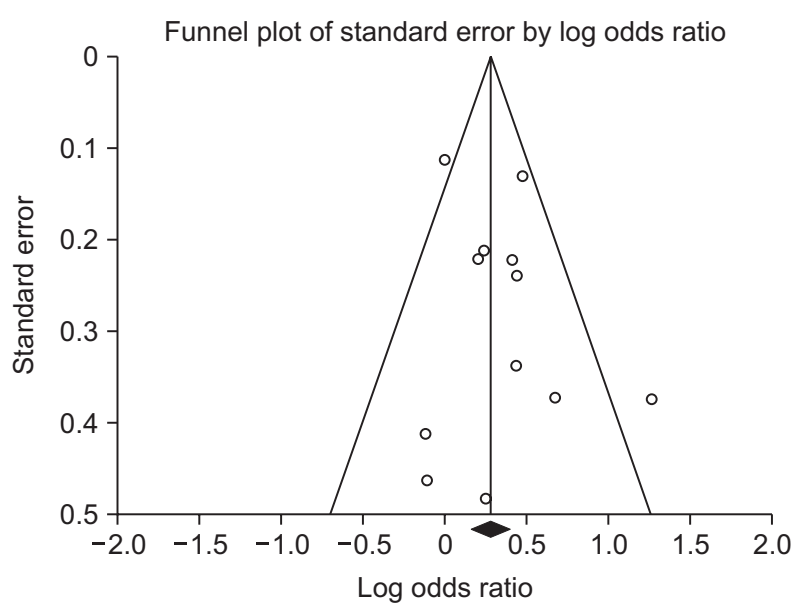

Fig. 3. Publication bias.

ticipants were more likely to be in the intensive care unit than non-CDI group participants (58.32\% vs 39.57\%, p<0.001).

Fig. 2 presents meta-analysis results, CDI risk comparisons between PPI and H2RA. PPIs were associated with an increase in CDI occurrence risk (pooled OR, 1.386; 95\% CI, 1.152 to 1.668; $\mathrm{p}=0.001)$. Heterogeneity was low $(\mathrm{n}=4, \mathrm{Q}=7.639, \mathrm{p}=0.157$, 
A

Study name

\begin{tabular}{|c|c|c|c|c|}
\hline & $\begin{array}{l}\text { Odds } \\
\text { ratio }\end{array}$ & $\begin{array}{l}\text { Lower } \\
\text { limit }\end{array}$ & $\begin{array}{l}\text { Upper } \\
\text { limit }\end{array}$ & $p$-value \\
\hline Shah et al. $(2000)^{5}$ & 0.889 & 0.397 & 1.993 & 0.775 \\
\hline Muto et al. $(2005)^{6}$ & 1.281 & 0.846 & 1.939 & 0.242 \\
\hline Kazakova et al. (2006) ${ }^{7}$ & 1.286 & 0.500 & 3.306 & 0.602 \\
\hline Dubberke et al. (2007) ${ }^{9}$ & 1.000 & 0.802 & 1.248 & 0.998 \\
\hline Aseeri et al. $(2008)^{10}$ & 0.897 & 0.362 & 2.222 & 0.814 \\
\hline Howell et al. $(2010)^{11}$ & 1.611 & 1.245 & 2.084 & 0.000 \\
\hline Loo et al. $(2011)^{12}$ & 1.554 & 0.972 & 2.485 & 0.066 \\
\hline Stevens et al. $(2011)^{13}$ & 1.513 & 0.978 & 2.341 & 0.063 \\
\hline \multirow[t]{2}{*}{ Barletta et al. $(2013)^{14}$} & 1.227 & 0.795 & 1.894 & 0.355 \\
\hline & 1.273 & 1.085 & 1.495 & 0.003 \\
\hline
\end{tabular}

B

Study name

Jayatilaka et al. $(2007)^{8}$
Barletta et al. $(2013)^{14}$
Ro et al. $(2016)^{16}$

\begin{tabular}{cccc}
\multicolumn{5}{c}{ Statistics for each study } \\
$\begin{array}{c}\text { Odds } \\
\text { ratio }\end{array}$ & $\begin{array}{c}\text { Lower } \\
\text { limit }\end{array}$ & $\begin{array}{c}\text { Upper } \\
\text { limit }\end{array}$ & p-value \\
1.543 & 0.797 & 2.989 & 0.198 \\
1.962 & 0.945 & 4.072 & 0.071 \\
3.547 & 1.704 & 7.386 & 0.001 \\
2.167 & 1.335 & 3.517 & 0.002
\end{tabular}

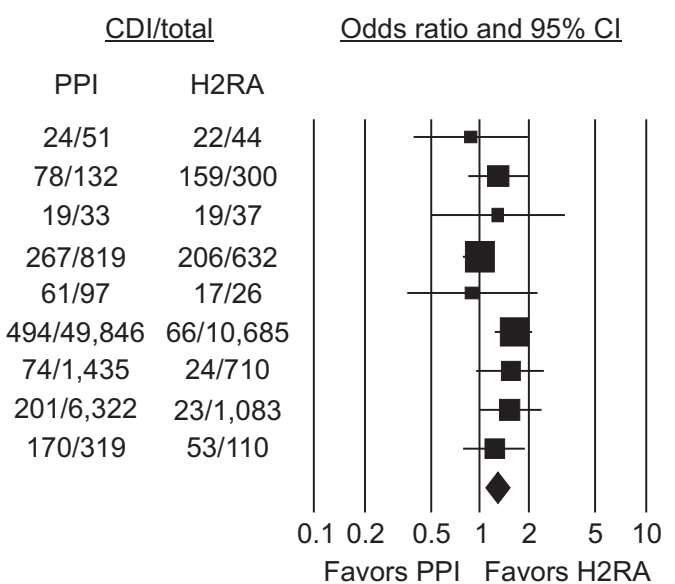

Relative Relative

weight weight

3.67

11.59

2.73

25.97

2.95

22.09

9.51

10.70

10.79

\begin{tabular}{cr}
\multicolumn{2}{c}{ CDI/total } \\
PPI & H2RA \\
$118 / 276$ & $15 / 46$ \\
$51 / 103$ & $15 / 45$ \\
$28 / 444$ & $10 / 537$ \\
&
\end{tabular}

\section{Odds ratio and $95 \% \mathrm{Cl}$}

Relative Relative weight weight

36.59

31.80

31.61

Fig. 4. Subgroup analysis by purpose of medication use; (A) unspecified and (B) prevention.

CDI, Clostridium difficile infection; CI, confidence interval; PPI, proton pump inhibitor; H2RA, histamine-2 receptor antagonist.

$\left.I^{2}=42.81 \%\right)$.

The quality of evidence started low because analyzed studies were all observational. Fig. 3 presents symmetrical funnel plot consistent with absence of publication bias. No evidence of publication bias by the Egger regression test for all-cause was found. The total number of study patients $(17,397)$ exceeded OIS $(6,220)$. The final quality of evidence remained low because no serious limitation was found in all domains of the GRADE system as shown in Table 2 .

Fig. 4 presented subgroup analysis results by the purpose of acid suppression therapy. Nine of 12 studies did not specify the purpose of therapy. Only three studies specified the purpose of therapy for prevention of gastric ulcers. PPIs were associated with an increase in CDI occurrence risk in both subgroups (unspecified purpose in Fig. 4A: pooled OR, 1.273; 95\% CI, 1.085 to $1.495 ; \mathrm{p}=0.003$, random effect, $I^{2}=22.9 \%$ and prevention purpose in Fig. 4B: pooled OR, 2.167; 95\% CI, 1.335 to 3.517; $\mathrm{p}=0.002$, random effect, $I^{2}=28.9 \%$ ). Subgroup analysis by intensive care unit (pooled OR, 1.616; 95\% CI, 1.112 to 2.347; $\mathrm{p}=0.012$ ) and non-intensive care unit (pooled OR, 1.321; 95\% CI, 1.11 to $1.563 ; p=0.001)$ confirmed consistent results that PPI is associated with higher CDI risk than H2RA. Subgroup analysis by study design confirmed consistency that PPI's CDI risk was higher than that of H2RA: nine case-control studies (pooled
OR, 1.166; 95\% CI, 1.003 to $1.355 ; \mathrm{p}=0.046)$; three cohort studies (pooled OR, 1.821; 95\% CI, 1.257 to 2.638; $\mathrm{p}=0.002$ ).

Dubberke et al.'s study ${ }^{9}$ could be an outlier resulting in increasing the degree of heterogeneity. When this study was removed from current meta-analysis, the magnitude of pooled OR increased to 1.492 (95\% CI, 1.279 to $1.741 ; \mathrm{p}<0.001)$ and heterogeneity dropped to near zero $\left(I^{2}=4.41 \%\right)$. Little is known whether either characteristic study design (nested case control), CDI definition (confirmation by stool toxin assay), or other factor in Dubberke et al.'s 2007 study would generate the outlier effect. $^{9}$

Meta-regression analysis found that there was absence of CDI predictor among age, gender, and antibiotics use. The results of meta-regression analysis were confirmed even at sensitivity analysis using a second-order term for age, gender, and antibiotics use.

\section{DISCUSSION}

To the best knowledge, the current meta-analysis is the first meta-analysis comparing CDI occurrence risk in two different stress ulcer treatment and prevention. Current meta-analysis found PPIs increased CDI occurrence risk by 38.6\% compared with H2RAs. 
Multiple medical societies have raised concerns about the unnecessary use of gastric acid suppression in the hospital. ${ }^{29,30}$ Indications for stress ulcer prophylaxis (SUP) in hospitalized patients have been identified in these literature: patients on mechanical ventilation and those with coagulopathy are strongly recommended. Other indications include prior history of GI bleeding, acute renal failure, high dose of steroids, burn, sepsis and increased severity of illness with prolonged intensive care unit stay. ${ }^{29,30}$ In critically ill patients, PPIs seem to be more effective than H2RAs in preventing overt upper GI bleeding. ${ }^{31}$ SUP use in lower risk groups is not specified by the professional societies. Indeed, SUP is commonly overused in hospitals, with as many as $71 \%$ of patients in general medicine wards receiving some sort of SUP without an appropriate indication. ${ }^{32}$ Anticoagulant therapy has been identified as a risk factor for GI bleeding in hospitalized patients, but the use of SUP has not been found to lower that risk. ${ }^{33}$ Therefore, routine use of SUP in non-ICU services should seriously be reconsidered. ${ }^{32,33}$ Moreover, future studies highlighting the comparative efficacy between PPI and H2RA among patients at low GI bleeding risk are needed. Studies have also shown better cost-effectiveness with the use of PPI compared to H2RA for SUP. ${ }^{34-36}$ However, applying these results to current practice would be limited because these studies did not include CDI occurrence as one of the outcomes. ${ }^{34-36}$

CDI is a significant burden on the health care system. CDI incidence in the United States has increased by approximately 3-fold between 2000 and 2012. ${ }^{2,37}$ In 2008, CDI may have resulted in as much as $\$ 4.8$ billion in excess healthcare costs in acute-care facilities alone. ${ }^{2,37}$ Additionally, it is critical to include cost as main outcome in future studies determining the choice of SUP use. It is also largely unknown which acid suppressive therapy group has better preventive efficacy than the other group in other conditions such as acute renal failure, sepsis, chronic steroid use, and burns. Further studies are urgently needed to compare the efficacy of H2RAs versus PPIs in these patient groups.

Current meta-analysis raised public concerns and suggests future studies. Olsen et al. ${ }^{38}$ analyzed nationally representing administrative databases and reported the incidence of CDI in Medicare population was 10-fold higher than that in the privately insured younger patients. Long-term PPI use in nursing homes could increase the risk of CDI occurrence, especially in elderly patients who have been recently discharged from hospital and are more vulnerable to intestinal mucosal injury. ${ }^{39}$ In addition, according to recent nationally representing database analysis, Medicare beneficiaries with recent hospitalization, invasive procedures, urinary tract infection, and pneumonia were more vulnerable to have the CDI. ${ }^{40}$ Public health dimension should identify more high risks and maximize the effectiveness of preventing CDI occurrence attributed by SUP from hospitallevel and regional health authorities' perspectives. Suggested future studies would be highlighted by exploring how these high risks on CDI would be influenced when PPI or H2RA is used for SUP.

Our confidence in current meta-analysis results is strengthened by the following few points. First, current meta-analysis has higher homogeneity $\left(I^{2}=42.81 \%\right)$ compared with previous meta-analyses as shown in Table 4 . Second, current metaanalysis focused on study participants to hospitalized adults. Current analysis findings could be more specifically applied to the development of hospital quality and infection control. Third, current meta-analysis was free of publication bias. For example,

Table 4. Meta-Analysis Comparisons of Acid Suppression Therapy and Clostridium difficile Infection

\begin{tabular}{|c|c|c|c|c|c|c|}
\hline Author (year) & Search engine & $\begin{array}{l}\text { Acid } \\
\text { suppression } \\
\text { therapy }\end{array}$ & $\begin{array}{l}\text { No. of } \\
\text { studies }\end{array}$ & $\begin{array}{c}\text { Degree of } \\
\text { heterogeneity }\left(I^{2}\right), \\
\%\end{array}$ & $\begin{array}{l}\text { Pooled effect } \\
\text { estimates, } \\
\text { OR }^{*}(95 \% \mathrm{CI})\end{array}$ & $\begin{array}{l}\text { Quality } \\
\text { grading } \\
\text { system }\end{array}$ \\
\hline Current study & $\begin{array}{l}\text { PubMed, MEDLINE/Ovid, } \\
\text { CINAHL, Web of Science, } \\
\text { and Google Scholar }\end{array}$ & PPI vs H2RA & 12 & 42.81 & $1.386(1.152-1.668)$ & GRADE \\
\hline Tleyjeh et al. $(2012)^{19}$ & $\begin{array}{l}\text { MEDLINE, EMBASE, Web of } \\
\text { Science, and Scopus }\end{array}$ & PPI vs control & 51 & 89.9 & $1.65(1.47-1.85)$ & $\begin{array}{l}\text { Newcastle- } \\
\text { Ottawa Scale; } \\
\text { GRADE }\end{array}$ \\
\hline Kwok et al. $(2012)^{20}$ & MEDLINE and EMBASE & PPI vs control & 39 & 85 & $1.74(1.47-2.85)$ & GRADE \\
\hline Janarthanan et al. $(2012)^{21}$ & MEDLINE & PPI vs control & 23 & 91.93 & 1.648 (1.424-1.908) & MOOSE \\
\hline Deshpande et al. (2012) & $\begin{array}{l}\text { MEDLINE, CINAHL, Cochrane, } \\
\text { Web of Science, and Scopus }\end{array}$ & PPI vs control & 30 & 87 & $2.15(1.81-2.55)$ & MOOSE \\
\hline
\end{tabular}

OR, odds ratio; CI, confidence interval; CINAHL, Cumulative Index of Nursing and Allied Health Literature; PPI, proton pump inhibitor; H2RA, histamine-2 receptor antagonist; GRADE, Grading of Recommendations Assessment Development and Evaluations; MOOSE, Meta-Analysis of Observational Studies in Epidemiology.

${ }^{*} \mathrm{OR}>1$ indicates that PPIs increase the risk of $C$. difficile infection compared to H2RAs (current meta-analysis) or the control (Tleyjeh, Kwok, Janarthanan, and Desphpande's meta-analyses). 
newer studies were added after previous meta-analyses were published in 2012 and studies of small number cases $(n<10)$ were excluded. Lastly, subgroup analysis results confirmed consistency of current meta-analysis results.

We acknowledge several limitations in the current meta-analysis. First, the diagnosis methods of CDI occurrence were not unified by the microbiologic or/and clinical diagnosis. Second, despite being an important risk factor for CDI, we could not obtain information on the specific dose, duration and frequency of the antibiotics used in most of the included studies. We could not perform further analysis to investigate the potential influence of antibiotics use. Third, the purpose of current analysis was not aimed at evaluating other comparative efficacies between PPI and H2RA (e.g., GI bleeding prevention). Finally, more specific H2RA and PPI use data (strength and duration) were not reported. Therefore, current meta-analysis findings should be interpreted with caution.

In conclusions, in either prevention or treatment of stress ulcers, the use of PPIs was associated with increased risk of hospital-acquired CDI occurrence by $38.6 \%$ compared to the use of H2RAs.

\section{CONFLICTS OF INTEREST}

No potential conflict of interest relevant to this article was reported.

\section{ACKNOWLEDGEMENTS}

This work was supported by University of Nevada School of Medicine, Faculty Career Development Award (recipient: J.W.Y.).

Author contributions: M. Azab, D.H.D., L.D., Y.E., and J.W.Y. contributed to the conception and design; M. Azab, M. Ahmed, and J.J.C. contributed to the acquisition of data. D.H.D. and L.D. contributed to the quality assessment; X.B.L. and J.W.Y. undertook the statistical analysis; M. Azab, D.H.D., L.D., A.S., X.B.L., and J.W.Y. drafted the report and contributed to the critical revision of the manuscript.

\section{REFERENCES}

1. Bartlett JG, Moon N, Chang TW, Taylor N, Onderdonk AB. Role of Clostridium difficile in antibiotic-associated pseudomembranous colitis. Gastroenterology 1978;75:778-782.

2. Lessa FC, Mu Y, Bamberg WM, et al. Burden of Clostridium difficile infection in the United States. N Engl J Med 2015;372:825834.

3. McFarland LV, Mulligan ME, Kwok RY, Stamm WE. Nosocomial acquisition of Clostridium difficile infection. N Engl J Med 1989;320:204-210.

4. Samore MH, Venkataraman L, DeGirolami PC, Arbeit RD, Karchmer AW. Clinical and molecular epidemiology of sporadic and clustered cases of nosocomial Clostridium difficile diarrhea. Am J Med 1996;100:32-40.

5. Shah S, Lewis A, Leopold D, Dunstan F, Woodhouse K. Gastric acid suppression does not promote clostridial diarrhoea in the elderly. QJM 2000;93:175-181.

6. Muto CA, Pokrywka M, Shutt K, et al. A large outbreak of Clostridium difficile-associated disease with an unexpected proportion of deaths and colectomies at a teaching hospital following increased fluoroquinolone use. Infect Control Hosp Epidemiol 2005;26:273-280.

7. Kazakova SV, Ware K, Baughman B, et al. A hospital outbreak of diarrhea due to an emerging epidemic strain of Clostridium difficile. Arch Intern Med 2006;166:2518-2524.

8. Jayatilaka S, Shakov R, Eddi R, Bakaj G, Baddoura WJ, DeBari VA. Clostridium difficile infection in an urban medical center: five-year analysis of infection rates among adult admissions and association with the use of proton pump inhibitors. Ann Clin Lab Sci 2007;37:241-247.

9. Dubberke ER, Reske KA, Olsen MA, et al. Evaluation of Clostridium difficile-associated disease pressure as a risk factor for $\mathrm{C}$ difficile-associated disease. Arch Intern Med 2007;167:1092-1097.

10. Aseeri M, Schroeder T, Kramer J, Zackula R. Gastric acid suppression by proton pump inhibitors as a risk factor for clostridium difficile-associated diarrhea in hospitalized patients. Am J Gastroenterol 2008;103:2308-2313.

11. Howell MD, Novack V, Grgurich P, et al. Iatrogenic gastric acid suppression and the risk of nosocomial Clostridium difficile infection. Arch Intern Med 2010;170:784-790.

12. Loo VG, Bourgault AM, Poirier L, et al. Host and pathogen factors for Clostridium difficile infection and colonization. N Engl J Med 2011;365:1693-1703.

13. Stevens V, Dumyati G, Brown J, Wijngaarden E. Differential risk of Clostridium difficile infection with proton pump inhibitor use by level of antibiotic exposure. Pharmacoepidemiol Drug Saf 2011;20:1035-1042.

14. Barletta JF, El-Ibiary SY, Davis LE, Nguyen B, Raney CR. Proton pump inhibitors and the risk for hospital-acquired Clostridium difficile infection. Mayo Clin Proc 2013;88:1085-1090.

15. Barletta JF, Sclar DA. Proton pump inhibitors increase the risk for hospital-acquired Clostridium difficile infection in critically ill patients. Crit Care 2014;18:714.

16. Ro Y, Eun CS, Kim HS, et al. Risk of Clostridium difficile infection with the use of a proton pump inhibitor for stress ulcer prophylaxis in critically Ill patients. Gut Liver 2016;10:581-586.

17. Thorens J, Froehlich F, Schwizer W, et al. Bacterial overgrowth during treatment with omeprazole compared with cimetidine: a prospective randomised double blind study. Gut 1996;39:54-59.

18. U.S. Food \& Drug Administration. Drug safety communication: Clostridium difficile-associated diarrhea can be associated with stomach acid drugs known as proton pump inhibitors (PPIs) [Internet]. Silver Spring: FDA; c2016 [cited 2016 Nov 10]. Available from: http://www.fda.gov/Drugs/DrugSafety/ucm290510.htm. 
19. Tleyjeh IM, Bin Abdulhak AA, Riaz M, et al. Association between proton pump inhibitor therapy and clostridium difficile infection: a contemporary systematic review and meta-analysis. PLoS One 2012;7:e50836.

20. Kwok CS, Arthur AK, Anibueze CI, Singh S, Cavallazzi R, Loke YK. Risk of Clostridium difficile infection with acid suppressing drugs and antibiotics: meta-analysis. Am J Gastroenterol 2012;107:1011-1019.

21. Janarthanan S, Ditah I, Adler DG, Ehrinpreis MN. Clostridium difficile-associated diarrhea and proton pump inhibitor therapy: a meta-analysis. Am J Gastroenterol 2012;107:1001-1010.

22. Deshpande A, Pant C, Pasupuleti V, et al. Association between proton pump inhibitor therapy and Clostridium difficile infection in a meta-analysis. Clin Gastroenterol Hepatol 2012;10:225-233.

23. MacLaren R, Reynolds PM, Allen RR. Histamine-2 receptor antagonists vs proton pump inhibitors on gastrointestinal tract hemorrhage and infectious complications in the intensive care unit. JAMA Intern Med 2014;174:564-574.

24. Moher D, Liberati A, Tetzlaff J, Altman DG; PRISMA Group. Preferred reporting items for systematic reviews and meta-analyses: the PRISMA statement. Ann Intern Med 2009;151:264-269.

25. Guyatt GH, Oxman AD, Vist GE, et al. GRADE: an emerging consensus on rating quality of evidence and strength of recommendations. BMJ 2008;336:924-926.

26. Guyatt GH, Oxman AD, Kunz R, et al. GRADE guidelines 6 . Rating the quality of evidence: imprecision. J Clin Epidemiol 2011;64:1283-1293.

27. GRADEpro [Internet]. Hamilton: McMaster University; 2015 [cited 2016 Nov 10]. Available from: http://www.guidelinedevelopment. org.

28. DerSimonian R, Laird N. Meta-analysis in clinical trials. Control Clin Trials 1986;7:177-188.

29. ASHP therapeutic guidelines on stress ulcer prophylaxis: ASHP Commission on Therapeutics and approved by the ASHP board of directors on November 14, 1998. Am J Health Syst Pharm 1999;56:347-379.

30. Guillamondegui OD, Gunter OL, Bonadies JA, et al. Practice management guidelines for stress ulcer prophylaxis: EAST Prac- tice Management Guidelines Committee [Internet]. Chicago: Eastern Association for the Surgery of Trauma; c2008 [cited 2016 Nov 10]. Available from: http://www.east.org/education/ practice-management-guidelines/stress-ulcer-prophylaxis.

31. Cook DJ, Griffith LE, Walter SD, et al. The attributable mortality and length of intensive care unit stay of clinically important gastrointestinal bleeding in critically ill patients. Crit Care 2001;5:368375.

32. Grube RR, May DB. Stress ulcer prophylaxis in hospitalized patients not in intensive care units. Am J Health Syst Pharm 2007;64:1396-1400.

33. Choudhry MN, Soran H, Ziglam HM. Overuse and inappropriate prescribing of proton pump inhibitors in patients with Clostridium difficile-associated disease. QJM 2008;101:445-448.

34. Alhazzani W, Alenezi F, Jaeschke RZ, Moayyedi P, Cook DJ. Proton pump inhibitors versus histamine 2 receptor antagonists for stress ulcer prophylaxis in critically ill patients: a systematic review and meta-analysis. Crit Care Med 2013;41:693-705.

35. Barkun AN, Adam V, Martel M, Bardou M. Cost-effectiveness analysis: stress ulcer bleeding prophylaxis with proton pump inhibitors, H2 receptor antagonists. Value Health 2013;16:14-22.

36. Harris RA, Kuppermann M, Richter JE. Proton pump inhibitors or histamine-2 receptor antagonists for the prevention of recurrences of erosive reflux esophagitis: a cost-effectiveness analysis. Am J Gastroenterol 1997;92:2179-2187.

37. Dubberke ER, Olsen MA. Burden of Clostridium difficile on the healthcare system. Clin Infect Dis 2012;55 Suppl 2:S88-S92.

38. Olsen MA, Young-Xu Y, Stwalley D, et al. The burden of Clostridium difficile infection: estimates of the incidence of CDI from U.S. administrative databases. BMC Infect Dis 2016;16:177.

39. Al-Tureihi FI, Hassoun A, Wolf-Klein G, Isenberg H. Albumin, length of stay, and proton pump inhibitors: key factors in Clostridium difficile-associated disease in nursing home patients. J Am Med Dir Assoc 2005;6:105-108.

40. Dubberke ER, Olsen MA, Stwalley D, et al. Identification of medicare recipients at highest risk for Clostridium difficile infection in the US by population attributable risk analysis. PLoS One 2016;11:e0146822. 